
3 Research Square
Preprints are preliminary reports that have not undergone peer review.
They should not be considered conclusive, used to inform clinical practice, or referenced by the media as validated information.

\title{
Comparison of Awareness and Attitudes Toward Advance Care Planning Between Chinese Medical and Non-medical University Students
}

Min Liu

Philippine Women's University

Fanqi Meng ( $\Delta$ Imin89@163.com)

Yancheng Teachers'University

Wenmin Sun

The First people's Hospital of Yancheng

Dandan Li

Kangda College of Nanjing Medical University

Jing Sun

The First people's Hospital of Yancheng

\section{Research Article}

Keywords: University students, Advance care planning, Awareness, Palliative care, China

Posted Date: May 24th, 2021

DOl: https://doi.org/10.21203/rs.3.rs-505201/v1

License: (9) This work is licensed under a Creative Commons Attribution 4.0 International License. Read Full License 


\section{Abstract}

Background: To date, there is a paucity of information on the discrepancies of awareness and attitudes towards ACP among university students in mainland China. The purposes of this study are to investigate the discrepancies in the awareness and attitudes toward advance care planning (ACP) between Chinese medical and non-medical university students and to identify the association between the awareness and attitudes toward ACP and medical education. A total of 718 university students included 290 medical students and 428 non-medical students from 12 universities in 4 provinces in mainland China were surveyed by using the Advance Care Planning Questionnaire (ACPQ).

Results: More than half of the university students (59.89\%) had never heard of ACP before; there were significant differences in the awareness regarding ACP between medical students and their non-medical peers $(P<0.05) ; 82.45 \%$ of participants were more likely to consider discussing ACP in the future; there was no significant difference $(P>0.05)$ in the previous experience last 5 years between the two groups except the item of "have been involved in the decision making of your treatment" ( $P=0.005)$; univariate analysis and multivariate linear regression analysis showed that medical education was the factor influencing the awareness of end-of-life $(P=0.000)$ and proxy decision-maker $(P=0.028)$ among university students.

Conclusion: The awareness toward ACP of university students in mainland China remained limited, but their attitudes were positive. Medical students had a higher level of awareness regarding ACP than nonmedical students, and medical education was the factor that promoted students to understand end-of-life care and proxy decision-maker. Establishing educational initiatives, developing models for peer-led ACP, and perfecting governmental policies should be emphasized.

\section{Background}

Advance care planning (ACP) is an ongoing process that allows competent individuals to share life goals, personal values, and end-of-life treatment preferences with healthcare providers and their families [1]. As the core element of palliative care, ACP is an effective way to help patients make decisions regarding lifesustaining treatment and end-of-life care for themselves [2]. It not only guarantees patients' healthcare autonomy and dignity, promotes communications among patients, their families, and healthcare providers, but relieves the family burden of end-of-life decision-making and reduces family conflict $[3,4]$. Nowadays, it has been implemented in the UK [5], America [6], Canada [7], Australia [8], Singapore [9], Taiwan Province [10], and Hong Kong [11] in China. However, the research on ACP in mainland China is still in its infancy [12].

Since the 13th Five-Year Plan for Healthy Aging that emphasized satisfy the needs of the end-of-life patients had been issued by the National Health Commission in 2017, ACP has received unprecedented attention in mainland China [13]. University students, as the future backbone of the society, may play important roles in initiating and facilitating end-of-life discussions and be instrumental in ACP for their 
elders [14]. Although the great awareness and positive attitudes regarding ACP among university students will promote the spread and the development of ACP in public [15], there is a paucity of information on their awareness and attitudes towards ACP in mainland China. We conducted a cross-sectional study of 18-23-year-old university students included medical and non-medical students recruited from 12 public universities in 4 provinces in the east part of China. The specific purposes were: 1) to investigate the discrepancies in the awareness and attitudes toward ACP between Chinese medical and non-medical university students; 2 ) to identify the association between the awareness and attitudes toward ACP and medical education.

\section{Methods}

\section{Study design}

This was a descriptive, cross-sectional study conducted in 2021 by convenience sampling. The research method was compliant with the Strengthening the Reporting of Observational Studies in Epidemiology (STROBE) checklist (Appendix 1).

\section{Study setting and study participants}

A total of 718 students that included 290 medical university students (from School of Nursing, School of Pharmacy, School of Medical Technology) and 428 non-medical university students (from School of Education, School of Business, School of Mathematics, School of Statistics) from 12 universities in 4 provinces (Jiangsu Province, Shandong Province, Zhejiang Province, Anhui Province) were surveyed. All universities were public, and participants were recruited in the study if they: (1) aged 18-23-year- old; (2) agreed to participate in this study. Students in their fourth year of the university were excluded.

\section{Survey methods}

An online survey was created by WenJuanXing that was a professional online questionnaire survey tool and an electronic database where data was uploaded automatically. Then, a quick response code and a web link for the survey were created, through which the students could access the questionnaire. An invitation was given by WeChat, the largest social media platform in China, to describe the purposes, contents, risks, benefits, and length of the survey. We emphasized the voluntary participation, the implied consent, the confidentiality of the study, and our gratefulness for the participants before data collection. We had distributed questionnaires to medical and non-medical university students on different days. The completion and submission of the questionnaire were regarded as implied consent to participate in the study, and respondents could get 10 RMB (about \$2) electronic red packets upon completion of the survey.

\section{Survey tools}

The Advance Care Planning Questionnaire (ACPQ) developed by Lai et al. [16] to assess awareness, attitudes, and acceptance of ACP in Malaysian in 2016 was used in this study. It was translated into 
Chinese by Zhu et al. in 2020 [17]. The ACPQ contained four domains, 1) Demographic information: there were sex, age, marital status, ethnicity, occupation, etc. 2) Health information: there were the self-rated health status (from very poor to excellent) and the current medical illness. 3) Awareness on ACP: five terminologies were used to assess whether the participant had ever heard, respectively ACP, proxy decision-maker, end-of-life decision making, living will, and power of attorney. There were 3 response options, respectively "yes", "yes, but I am unsure of its meaning", and "no". The internal consistency of this questionnaire was 0.885. 4) Attitudes on ACP: there were 18 items of which included 1 question regarding the participants' previous experience in the last five years, 1 item of the willingness of discussing ACP in the future, the rest of the items were measured on a 5-point Likert scale (from "strongly agree" to "strongly disagree") that was designed to assess under what circumstances the participant would feel it be better or not be better to express their living wishes. It had been reported that the internal consistency was 0.708 , and the scale-content validity index of this Chinese version of the ACPQ was 0.921 [17].

\section{Data collection}

Researchers asked members of the Chinese Young Teacher Association that were university teachers from different regions across mainland China to help send questionnaires to their students via WeChat. Participants answered the online questionnaire survey through WeChat with either mobile phones or computers. All questionnaires were stored on the WenJuanXing database, including the answering date, IP address, participants' positions, and the responses to the survey.

\section{Data analysis}

The statistical analysis was carried out by SPSS Statistics software (version22.0; International Business Machines, Corp, Armonk, New York) into which all data were entered by double entry. Frequencies and percentages (\%) were calculated for categorical data. Chi-square test for categorical data in the bivariate analyses and Wilcoxon signed-rank test for ranked ordinal data were used to compare the differences of demographics, attitudes, and awareness between medical university students and non-medical university students. Binomial logistic regression was carried out for multivariate analysis to evaluate the association between medical education and the awareness and attitudes of ACP among university students. Differences were considered statistically significant when $\mathrm{P}<0.05$.

\section{Results}

\section{Demographic characteristics}

In the study, 966 questionnaires had been sent out to 318 medical university students and 648 nonmedical university students. A total of 771 questionnaires were recovered, including 303 (39.30\%) questionnaires from medical university students and $468(60.70 \%)$ questionnaires from non-medical university students. The response rate to this survey was $79.81 \%$, and the reasons for non-participation may because of the special sensitivities of the topic. After the manual screening, 53 invalid 
questionnaires were eliminated by a researcher, and 718 valid questionnaires were included in the final analysis, with $93.13 \%$ efficiency. In these valid questionnaires, 290 (40.39\%) from medical university students, and 428 (59.61\%) from non-medical university students.

Table 1 shows the sociodemographic characteristics and health information. Among the respondents, $80.50 \%$ of them were female; $95.96 \%$ of them were not married; $95.40 \%$ of them did not have a religion. There were $91.78 \%$ of participants who reported that they did not have any disease, while 3 students had diabetes and 5 students had cardiovascular diseases; the majority of students reported their health status were "excellent" or "very good" (74.09\%). There is no baseline information difference (all P $>0.05$ ) between the two groups. 
Table 1

Comparison of descriptive characteristics of medical and non-medical university students

\begin{tabular}{|c|c|c|c|c|c|c|c|c|}
\hline \multirow[b]{2}{*}{ Characteristics } & \multicolumn{2}{|c|}{$\begin{array}{l}\text { Total sample (n } \\
=718)\end{array}$} & \multicolumn{2}{|c|}{$\begin{array}{l}\text { Medical } \\
\text { students } \\
(n=290)\end{array}$} & \multicolumn{2}{|c|}{$\begin{array}{l}\text { Non-medical } \\
\text { students } \\
(n=428)\end{array}$} & \multirow[b]{2}{*}{ Statistics } & \\
\hline & $\mathbf{n}$ & $\%$ & $\mathbf{n}$ & $\%$ & n & $\%$ & & \\
\hline \multicolumn{9}{|l|}{ Gender } \\
\hline Male & 140 & 19.50 & 51 & 17.59 & 89 & 20.79 & \multirow{2}{*}{$x^{2}=1.134$} & \multirow[t]{2}{*}{$P=0.287$} \\
\hline Female & 578 & 80.50 & 239 & 82.41 & 339 & 79.21 & & \\
\hline \multicolumn{9}{|l|}{ Marital status } \\
\hline Unmarried & 689 & 95.96 & 283 & 97.59 & 406 & 94.86 & \multirow[t]{2}{*}{$x^{2}=3.315$} & \multirow[t]{2}{*}{$P=0.069$} \\
\hline Married & 29 & 4.04 & 7 & 2.41 & 22 & 5.14 & & \\
\hline \multicolumn{9}{|l|}{ Religiosity } \\
\hline None & 685 & 95.40 & 272 & 93.79 & 413 & 96.50 & \multirow[t]{4}{*}{$\mathrm{FE}$} & \multirow[t]{4}{*}{$P=0.358$} \\
\hline Buddhism & 11 & 1.53 & 6 & 2.07 & 5 & 1.17 & & \\
\hline Christianity & 16 & 2.23 & 9 & 3.10 & 7 & 1.64 & & \\
\hline Other & 6 & 0.84 & 3 & 1.03 & 3 & 0.70 & & \\
\hline \multicolumn{9}{|c|}{ Current medical illness } \\
\hline None & 659 & 91.78 & 264 & 91.03 & 395 & 92.29 & $x^{2}=0.361$ & $P=0.548$ \\
\hline $\begin{array}{l}\text { Cardiovascular } \\
\text { disease }\end{array}$ & 5 & 0.70 & 3 & 1.03 & 2 & 0.47 & $\mathrm{FE}$ & $P=0.398$ \\
\hline Diabetes & 3 & 0.42 & 2 & 0.69 & 1 & 0.23 & $\mathrm{FE}$ & $P=0.569$ \\
\hline Other & 51 & 7.10 & 21 & 7.24 & 30 & 7.01 & $x^{2}=0.014$ & $P=0.905$ \\
\hline \multicolumn{9}{|c|}{ Self-rated health status } \\
\hline Excellent & 204 & 28.41 & 83 & 28.62 & 121 & 28.27 & \multirow[t]{5}{*}{$Z=-1.380$} & \multirow[t]{5}{*}{$P=0.168$} \\
\hline Very good & 328 & 45.68 & 145 & 50.00 & 183 & 42.76 & & \\
\hline Good & 172 & 23.96 & 57 & 19.66 & 115 & 26.87 & & \\
\hline Poor & 13 & 1.81 & 5 & 1.72 & 8 & 1.87 & & \\
\hline Very poor & 1 & 0.14 & 0 & 0.00 & 1 & 0.23 & & \\
\hline
\end{tabular}

Legend: FE = Fisher exact test. 


\section{Awareness of ACP}

Table 2 displays that more than half (59.89\%) of all students reported they had never heard of ACP before. Non-medical students had a significantly lower level of awareness of all these five terminologies on ACP overall than their medical peers (all $\mathrm{P}<0.05)$. 
Table 2

Comparison of the awareness of medical and non-medical university students

\begin{tabular}{|c|c|c|c|c|c|c|c|c|}
\hline \multirow[b]{2}{*}{ Characteristics } & \multicolumn{2}{|c|}{$\begin{array}{l}\text { Total sample }(n= \\
718)\end{array}$} & \multicolumn{2}{|c|}{$\begin{array}{l}\text { Medical } \\
\text { students } \\
(n=290)\end{array}$} & \multicolumn{2}{|c|}{$\begin{array}{l}\text { Non-medical } \\
\text { students } \\
(n=428)\end{array}$} & \multirow[b]{2}{*}{$\mathbf{Z}$} & \multirow[b]{2}{*}{$\mathbf{P}$} \\
\hline & $\mathbf{n}$ & $\%$ & $\mathbf{n}$ & $\%$ & $\mathrm{n}$ & $\%$ & & \\
\hline \multicolumn{9}{|l|}{ ACP } \\
\hline Yes & 76 & 10.58 & 46 & 15.86 & 30 & 7.01 & \multirow[t]{3}{*}{-8.049} & \multirow[t]{3}{*}{0.000} \\
\hline $\begin{array}{l}\text { Yes, but } \\
\text { unsure }\end{array}$ & 212 & 29.53 & 123 & 42.41 & 89 & 20.79 & & \\
\hline No & 430 & 59.89 & 121 & 41.72 & 309 & 72.20 & & \\
\hline \multicolumn{9}{|c|}{ End-of-life decision making } \\
\hline Yes & 173 & 24.09 & 129 & 44.48 & 44 & 10.28 & \multirow[t]{3}{*}{-9.729} & \multirow[t]{3}{*}{0.000} \\
\hline $\begin{array}{l}\text { Yes, but } \\
\text { unsure }\end{array}$ & 301 & 41.92 & 102 & 35.17 & 199 & 46.50 & & \\
\hline No & 244 & 33.98 & 59 & 20.34 & 185 & 43.22 & & \\
\hline \multicolumn{9}{|c|}{ Proxy decision-maker } \\
\hline Yes & 147 & 20.47 & 115 & 39.66 & 32 & 7.48 & \multirow[t]{3}{*}{-8.863} & \multirow[t]{3}{*}{0.000} \\
\hline $\begin{array}{l}\text { Yes, but } \\
\text { unsure }\end{array}$ & 262 & 36.49 & 89 & 30.69 & 173 & 40.42 & & \\
\hline No & 309 & 43.04 & 86 & 29.66 & 223 & 52.10 & & \\
\hline \multicolumn{9}{|l|}{ Living will } \\
\hline Yes & 148 & 20.61 & 86 & 29.66 & 62 & 14.49 & \multirow[t]{3}{*}{-6.054} & \multirow[t]{3}{*}{0.000} \\
\hline $\begin{array}{l}\text { Yes, but } \\
\text { unsure }\end{array}$ & 409 & 56.96 & 165 & 56.90 & 244 & 57.01 & & \\
\hline No & 161 & 22.42 & 39 & 13.45 & 122 & 28.50 & & \\
\hline \multicolumn{9}{|c|}{ Power of attorney } \\
\hline Yes & 102 & 14.21 & 56 & 19.31 & 46 & 10.75 & \multirow[t]{3}{*}{-5.189} & \multirow[t]{3}{*}{0.000} \\
\hline $\begin{array}{l}\text { Yes, but } \\
\text { unsure }\end{array}$ & 398 & 55.43 & 175 & 60.34 & 223 & 52.10 & & \\
\hline No & 218 & 30.36 & 59 & 20.34 & 159 & 37.15 & & \\
\hline
\end{tabular}

Legend: $\mathrm{ACP}=$ advance care planning. 


\section{Attitudes of ACP}

Table 3 presents that $82.45 \%$ of participants who engaged in this research were more likely to discuss ACP in the future. There was no significant difference in the previous experience of the last 5 years between the two groups $(P>0.05)$ except the item of "have been involved in the decision making of your treatment" $(P=0.005)$.

Table 3

Comparison of the attitudes of medical and non-medical university students

\begin{tabular}{|c|c|c|c|c|c|c|c|c|}
\hline \multirow[b]{2}{*}{ Characteristics } & \multicolumn{2}{|c|}{$\begin{array}{l}\text { Total sample } \\
(n=718)\end{array}$} & \multicolumn{2}{|c|}{$\begin{array}{l}\text { Medical } \\
\text { students } \\
(n=290)\end{array}$} & \multicolumn{2}{|c|}{$\begin{array}{l}\text { Non-medical } \\
\text { students } \\
(n=428)\end{array}$} & \multirow[b]{2}{*}{$x^{2}$} & \multirow[b]{2}{*}{$P$} \\
\hline & $\mathbf{n}$ & $\%$ & n & $\%$ & $\mathbf{n}$ & $\%$ & & \\
\hline \multicolumn{9}{|c|}{ Previous experience in the last 5 years } \\
\hline Hospitalized & 161 & 22.42 & 74 & 25.52 & 87 & 20.33 & 2.677 & 0.102 \\
\hline $\begin{array}{l}\text { Experience of the death of a } \\
\text { family member }\end{array}$ & 323 & 44.99 & 130 & 44.83 & 193 & 45.09 & 0.005 & 0.944 \\
\hline $\begin{array}{l}\text { Involving the care of family } \\
\text { member }\end{array}$ & 358 & 49.86 & 143 & 49.31 & 215 & 50.23 & 0.059 & 0.808 \\
\hline $\begin{array}{l}\text { Family member(s) or friend(s) } \\
\text { have experiences with LST }\end{array}$ & 100 & 13.93 & 47 & 16.21 & 53 & 12.38 & 2.108 & 0.146 \\
\hline $\begin{array}{l}\text { Involved in important treatment } \\
\text { decisions }\end{array}$ & 137 & 19.08 & 70 & 24.14 & 67 & 15.65 & 8.058 & 0.005 \\
\hline \multicolumn{9}{|c|}{ The willingness of discussing on ACP in the future } \\
\hline Yes & 592 & 82.45 & 240 & 82.75 & 352 & 82.24 & 0.032 & 0.859 \\
\hline No & 126 & 17.55 & 50 & 17.24 & 76 & 17.76 & & \\
\hline
\end{tabular}

Legend: $\mathrm{LST}=$ life-sustaining treatment; $\mathrm{ACP}=$ advance care planning.

\section{The association between the awareness and attitudes toward ACP and medical education}

According to the results of the univariate analysis in Table 2 and 3 , the differences between the two groups were significantly based on the awareness of ACP and the experience of making own treatment decisions. Multiple linear regression analyses were performed to further explore the association between the awareness and attitudes toward ACP and medical education. All five items of the awareness of ACP ("yes = 0", "yes, but I am unsure of its meaning = 1", and "no = 2") and the item of experience of making own treatment decisions ("yes $=0$ ", "no $=1$ ") were set as the independent factors. Medical students (with medical education)/non-medical students (without medical education) were set as dependent factors 
("medical students (with medical education) $=0$ ", "non-medical students (without medical education) $=$ 1 1"). Table 4 presents that medical education was the factor associated with the item of the end-of-life decision making $(P=0.000)$ and the item of the proxy decision-maker $(P=0.028)$.

Table 4

Multiple Logistic Regression Analysis of the awareness and attitudes of ACP affected by medical education.

\begin{tabular}{|llllllll|}
\hline Predictors & $\boldsymbol{\beta}$ & $\mathbf{S E}$ & $\begin{array}{l}\text { Wald } \\
\boldsymbol{\chi}^{2}\end{array}$ & OR & $95 \% \mathrm{Cl}$ & $\mathbf{P}$ \\
\hline ACP & -0.214 & 0.159 & 1.819 & 0.807 & 0.591 & 1.102 & 0.177 \\
\hline End-of-life decision making & -0.723 & 0.180 & 16.087 & 0.485 & 0.341 & 0.691 & 0.000 \\
\hline Proxy decision-maker & -0.406 & 0.185 & 4.827 & 0.667 & 0.464 & 0.957 & 0.028 \\
\hline Living will & -0.155 & 0.207 & 0.560 & 0.856 & 0.570 & 1.286 & 0.454 \\
\hline Power of attorney & 0.343 & 0.211 & 2.647 & 1.409 & 0.932 & 2.129 & 0.104 \\
\hline $\begin{array}{l}\text { Involved in important treatment } \\
\text { decisions }\end{array}$ & -0.249 & 0.208 & 1.429 & 0.779 & 0.518 & 1.173 & 0.232 \\
\hline
\end{tabular}

Legend: $\mathrm{SE}$ = standard error; $\mathrm{Cl}$ = confidence interval; $\mathrm{OR}$ = odds ratio; $\mathrm{ACP}$ = advance care planning.

\section{Discussion}

To our knowledge, this is one of the first national studies to investigate the discrepancies among the awareness and attitudes toward ACP between medical and non-medical university students in mainland China. The study provides additional information about influence factors related to the awareness and attitudes of ACP among university students. These findings are useful for the development of suitable interventions to improve the awareness and attitudes toward ACP of university students and to help them make appropriate decisions for elders and their own eventual ACP process, even if it does not occur in the future.

In the study, $59.89 \%$ of the students had never heard of ACP, which is lower than a previous survey of awareness of ACP among adolescents at 14 to 21 years of age (72\%) in America [18], but it is similar to a recent study of undergraduate nursing students (65.9\%) in China [15]. The low level of awareness of ACP among university students in mainland China was mainly related to the lack of advanced medical education. The results also showed that medical students have higher levels of awareness than nonmedical students, which was congruent with the findings in a study that emphasized the impact of training courses concerning ACP on university students [19]. Regarding the difference in awareness toward ACP between medical and non-medical students, the government should focus on health education, such as life-death education on university students. 
Despite under-education on ACP, the majority of participants showed positive attitudes toward it, and the results of this study had documented their strong willingness to engage in ACP discussion in the future (82.45\%). This result is inconsistent with that among American university students, which reported lower willingness levels (73\%) in creating an advance directive. The high willingness rate in our study may be related to the reported grade, religion, and education. Firstly, we excluded senior students as they were in their internships. However, it has been reported that university students in the first 3 grades had a stronger willingness to participate in ACP than their seniors. This may be due to that they were younger, more premature, and did not know the difficulties in the implementation of ACP in real life[15]. Secondly, $95.4 \%$ of the participants in the study had reported no religion. It has also been shown that university students who had no religion were more likely to carry out ACP than those who had a religion [15]. Thirdly, all participants recruited in this study were university students who had high education levels. In the previous studies, higher education was associated with greater awareness and preference for ACP $[2,3,20]$. Therefore, from our perspective, as a well-educated population without any religions, university students had open-minded thinking and a higher proportion of considering ACP. They may be less influenced by Chinese traditional culture and death taboo compared to those who have lower education levels. It may be that all these factors lead to the statistical balance of the level of willingness between medical and non-medical students. This unexpected result was found to be similar to a recent study of the attitudes toward ACP among Chinese clinical nurses which showed that the nurses who did not receive any school education of palliative care were more likely to participate in ACP than those who had relevant knowledge [21]. This study also found that medical students had more experience in making their own treatment decisions $(P=0.005)$ than non-medical students. A possible explanation is a professional knowledge including medicine, nursing, clinical practice, and medical ethics influenced medical students' autonomy and self-determination.

In the study, the more medical education the university students had, the awareness of ACP and the involvement in important treatment decisions were better. It has been discovered that medical education was the factor that influenced the awareness of the proxy decision-maker $(P=0.028)$ and the end-of-life decision making $(P=0.000)$ among university students, which was consistent with findings in the other study [22]. In China, medical education has an unignorable promoting influence on the awareness of ACP. When medical students were equipped with medical knowledge, they would better be prepared to understand and facilitate ACP discussions.

To date, many studies regarding ACP have focused on older adults. As a major force for positive social and economic change, university students are needed to be studied. Since university students are in the process of psychological development and identity transitions, their knowledge of ACP and competence relating to ethical end-of-life decision-making are proved to be deficient. This will result in their families and themselves receiving unsatisfactory care near the end of their lives [23]. Therefore, more ACP educational interventions need to be put on young people especially these well-educated university students to help them make a better judgment at the end of life or act as surrogate decision-makers for their elders if needed. 


\section{Strengths and limitations}

This study contributes to the sparse information about the awareness and attitudes toward ACP among university students in mainland China. Due to all questionnaires were spread by their teachers through the WeChat group, the response rate $(79.81 \%)$ and the effective questionnaire rate $(93.13 \%)$ of the initial samples was relatively high. These high rates contributed to the reduction of the selection bias caused by the loss of samples and uncompleted answers.

However, several limitations in this research need to be acknowledged. Firstly, although participants came from 12 universities in 4 provinces, they were all living in the east part of China with higher GDP, so this student group cannot represent Chinese university students. Secondly, as the reliability of the Chinese version of the questionnaire can be accepted among university students, so we did not conduct a pilot study to test and improve it. Thirdly, as young adults have their particularities, most of them were single, healthy, living with their parents or roommates without too much social experience, many potential factors such as age, occupation, monthly income, and so on were not compared and discussed deeply. This may limit the generalizability of the findings of young populations.

Further studies of this population are needed to better understand the differences between medical and non-medical university students as well as appropriate interventions to redress the disparity and to improve the awareness and attitudes regarding ACP among university students.

\section{Implication}

Discrepancies mainly existed in the awareness of ACP among medical and non-medical university students, and it was similar to the results in a previous study [19]. In order to redress this disparity, firstly, educational initiatives such as establish general life-death courses and develop ACP training programs may help university students better understand end-of-life decision-making, facilitate ACP conversations, clarify their options, explore the values and preferences of themselves and others, and advocate ACP [24]. Secondly, it is imperative to build models for peer-led ACP initiatives. The social identity theory suggested that students may have been more receptive to the workshops because they were members of their ingroup. Therefore, the workshops on ACP with behind-the-scenes support from older professionals need to be developed and presented for university students to participate in ACP [25]. Thirdly, the policies, laws, and regulations on ACP should be established and perfected by the governmental departments to regulate the implementation of ACP in mainland China.

\section{Conclusion}

Although the awareness of university students in mainland China remained limited, they showed supportive attitudes toward ACP. In general, medical students had higher levels of awareness regarding ACP than non-medical students. This study also confirmed that medical education is the factor that promoted students to understand end-of-life and proxy decision-maker. As under-education on ACP 
among university students in mainland China, establishing educational initiatives, developing models for peer-led ACP, and perfecting governmental policies should be emphasized.

\section{Abbreviations}

ACP: Advance care planning

\section{Declarations}

\section{Ethics approval and consent to participate}

All research method was performed in accordance with the Declaration of Helsinki. We have acquired ethical approval from the Ethics Committee of the First people's Hospital of Yancheng (No: 2021-K028). Online informed consent was provided by the respondents before they completed the questionnaire. All participants were at least 18 years of age. Data collectors informed participants of their right to end the data collection event at any time or skip any questions. No personally identifiable information was collected.

\section{Consent for publication}

Not applicable.

\section{Availability of data and materials}

The datasets used and/or analysed during the current study are available from the corresponding author upon reasonable request.

\section{Competing interests}

The authors declare they have no competing interests.

\section{Funding}

The authors received no financial support for the research, authorship, and/or publication of this article.

\section{Authors' contributions}

M. L., F. M. and W. S. contributed to the conception and design of this research. W. S. and J. S. sent the questionnaires and collected the data from the university students through WenJuanXing. D. L. and F. M. analyzed the interpreted data. M. L. was the major contributor in writing the manuscript. D. L. and J. S. revised the preliminary manuscript for intellectual content. All authors read and approved the final manuscript.

\section{Acknowledgments}


We gratefully acknowledge the agreement to use the ACPQ in our research and professional guidance from Dr. Pauline Siew Mei Lai (the Department of Primary Care Medicine, University of Malaya Primary Care); the university students who participated in the study; Huanhuan Zhou, Yang Wang, Yanan Sun, Jian Wang, Xiaoli Lin, Zhenhua He, Jingjing Yuan, Ji Ren, Changxiu Qiao, Wei Liu for the spread of the questionnaires; Lei Lv for assistance with data management.

\section{References}

1. Wichmann AB, Dam HV, Thoonsen B, Boer TA, Engels Y, Groenewoud AS. Advance care planning conversations with palliative patients: looking through the GP's eyes. BMC Fam Pract. 2018;19:184.

2. Kermel-Schiffman I, Werner P. Knowledge regarding advance care planning: A systematic review. Arch Gerontol Geriat. 2017;73:133-142.

3. Zhang N, Ning XH, Zhu ML, Liu XH, Li JB, Liu Q. Attitudes towards advance care planning and healthcare autonomy among community-dwelling older adults in Beijing, China. BioMed Res Int. 2015;1:1-10.

4. Cheng SY, Lin CP, Chan HY, et al. Advance care planning in Asia culture. JPN J Cli Oncol. 2020;50(9):976-89.

5. Dixon J, Karagiannidou M, Knapp M. The effectiveness of advance care planning in improving endof-life outcomes for people with dementia and their carers: A systematic review and critical discussion. J Pain Symptom Manage. 2018;55(1):132-150.

6. Cotter VT, Spriggs M, Razzak R. Advance care planning in early-stage dementia. JNP. 2018;14(3),1427.

7. Howard M, Bernard C, Klein D, Elston D, Tan A, Slaven M. Barriers to and enablers of advance care planning with patients in primary care. Can Fam Physician. 2018;64:e190-8.

8. Ramachenderan J, Auret K. The Challenge of Perioperative Advance Care Planning. J Pain Symptom Manage. 2019;58(3):538-42.

9. Ng QX, Kuah ZT, Loo GJ, et al. Awareness and Attitudes of Community-Dwelling Individuals in Singapore towards Participating in Advance Care Planning. Ann Acad Med Singap. 2017;46(3):84-90.

10. Wang SC, Chang CJ, Fan SY, Wang YW, Chang SC, Sung HC. Development of an advance care planning booklet in Taiwan. Tzu Chi Medi J. 2015;27:170-4.

11. Cheung JTK, Au D, Ip AHF, et al. Barriers to advance care planning: a qualitative study of seriously ill Chinese patients and their families. BMC Palliative Care. 2020;19(1):80-9.

12. Deng RL, Wang SB, Zhang JH, Chen LL, Qiu YY, Yang L. To embed Advance Care Planning into the health care system in China in the vision of Chinese and western culture. Chi Nurs Manag. 2019;19(3):321-5.

13. National Health Commission of the People's Republic of China. Issued on the 13th Five-Year Plan for Healthy Aging. 
http://www.nhc.gov.cn/jtfzs/jslgf/201703/63ce9714ca164840be76b362856a6c5f.shtml? tdsourcetag=s_pcqq_aiomsg. Accessed 15 March 2021.

14. Tripken JL, Elrod CS. Young adults' perspectives on advance care planning. Am J Hosp Palliat Me. 2018;35(4):627-34.

15. Shi ZY, Li XL, Tang MY, Peng YY. Investigation and analysis of undergraduate nursing students' attitudes toward advanced care planning and their willingness to implement. Am J Hosp Palliat Me. 2020;37(8):613-8.

16. Pauline SM L, Salinah M M, Karuthan C, Sajaratulnisah O. The development and validation of the advance care planning questionnaire in Malaysia. BMC Medical Ethics. 2016;17:61.

17. Zhu TT, Zhang J, Shi Y, et al. Awareness and attitudes toward advance care planning among community-dwelling older adults in China: A mixed-methods study. Am J Hosp Palliat Me. 2020;37(9):743-9.

18. Garvie PA, He J, Wang J, D'Angelo LJ, Lyon ME. An exploratory survey of end-of-life attitudes, beliefs and experiences of adolescents with HIV/AIDS and their families. J Pain Symptom Manage. 2012;44(3): 373-85.

19. Green MJ, Levi BH. Teaching advance care planning to medical students with a computer-based decision aid. J Cancer Educ. 2011;26(1):82-91.

20. Black K, Reynolds SL, Osman H. Factors associated with advance care planning among older adults in Southwest Florida. J Appl Geronol. 2008;27:93.

21. Cheng QQ, Liu XY, Li XY, et al. Discrepancies among knowledge, practice, and attitudes towards advance care planning among Chinese clinical nurses: A national cross-sectional study. Appl Nurs Res. 2021;58:151409.

22. Alminoja A, Piili RP, Hinkka H, Mersanoja R, Hirvonen O, Tyynela-Korhonen K. Does decision-making in end-of-life care differ between graduating medical students and experienced physicians? In Vivo. 2019;33:903-9.

23. Chang HH, Hu EY, Tsai SSL, Yao CA, Chen CY, Chiu TY. Reflections on an End-of-life Care Course for Preclinical Medical Students. J Formos Med Assoc. 2009;108(8):636-43.

24. Yokoya S, Kizawa Y, Maeno T. Practice and perceived importance of advance care planning and difficulties in providing palliative care in geriatric health service facilities in Japan: A nationwide survey. Am J Hosp Palliat Me. 2018;35(3):464-72.

25. Barrison P, Davidson LG. Promotion of advance care planning among young adults: A pilot study of health engagement workshop feasibility, implementation, and efficacy. Am J Hosp Palliat Me. 2021;38(5):441-7.

\section{Supplementary Files}

This is a list of supplementary files associated with this preprint. Click to download. 
- Appendix1STROBE.docx

Page 16/16 